\title{
Crimen y costumbre en el barrio de Tepito: notas sobre una sustracción miserable
}

\author{
JOVANI RIVERA GUTIERREZ \\ Universidad Nacional Autónoma de México | Ciudad de México, México \\ jjrivra@gmail.com
}

DOI 10.11606/issn.2316-9133.v30i2pe187938

resumen Después de ser víctima por última vez de un robo en las inmediaciones de Tepito (espacio de la Ciudad de México en el que crecí), produje un relato del incidente a medio camino entre el diario de campo y el diario íntimo con el que me propuse analizar dos fenómenos: el primero son los principios que había incorporado durante mi socialización en el barrio y que en los viejos tiempos permitían administrar la ilegalidad, aunque siempre con límites, disrupciones o ajustes (como se sabe por los estereotipos e imágenes que circulan en la cultura pública nacional, los actos criminales siguen siendo cotidianos en Tepito); el segundo es una forma particular de robo a la que denominé sustracción miserable, un robo violento que dado su modus operandi es difícilmente perseguido o castigado y que propicia pequeñas transacciones que movilizan de manera constante algunas de las principales economías ilegales locales (el narcomenudeo, la compra/venta de mercancía robada).

palabras claves robo a mano armada, Tepito, crack, habitus
Crime and custom in the Tepito neighborhood: notes on a miserable abduction

abstract After being robbed for the last time in Tepito (the Mexico City neighborhood where I grew up), I produced an account of the incident halfway between the field diary and the private diary with which I proposed to analyze two phenomena: the first is the principles that I had incorporated during my socialization in the neighborhood and that in the old days allowed to manage illegality, although always with limits, disruptions or adjustments (as is known by the stereotypes and images that circulate in the national public culture, the robberies are everyday acts in Tepito). The second is a particular form of theft that I called miserable robbery, a violent robbery that, given its modus operandi, is hardly prosecuted or punished and that encourages small transactions that constantly mobilize some of the main illegal local economies (drug dealing, purchase / sale of stolen merchandise).

keywords armed robbery, Tepito, crack, habitus 
A Héctor que ahora vive en una salsa.

\section{Entérese de cómo robaron a un etnógrafo del barrio}

La trama que me llevó de regreso a la casa en la que crecí, en el barrio de Tepito, era digna de una novelita a lo Fante. ${ }^{1}$ Había entrado en uno de esos espacios nebulosos en los que todos mis pagos se habían retrasado y todos mis subcontratos como profesor estaban en veremos; es decir, que estaba imposibilitado para pagar mi renta. El fin de año previo al incidente que aquí me ocupa, visité a mi abuela materna y la encontré un poco delicada de salud, aunque todo parecía tener un origen emocional: estaba pasando demasiado tiempo en soledad. Ella me dijo que su casa siempre iba a ser mi casa y que tal vez era buena idea para ambos que contemplara mi regreso y lo viera como una suerte de pausa para, como se dice coloquialmente, "agarrar vuelo". Mis años de experiencia como etnógrafo y mi fascinación por Tepito y la identidad local, se habían agolpado y me tenían lo suficientemente receptivo a todo lo que ocurría. Durante meses, no fueron más que garabatos y pequeñas notas que no culminaban en nada. Hasta que una mañana de día festivo, me asaltaron por última vez en el barrio.

Aquel lunes, mi abuela salió muy temprano para una de sus caminatas matinales en un parque cercano y yo decidí que, ya que me encontraba solo, podía comprar un desayuno exprés en algún puesto callejero, para después enfocarme en mi rutina de preparar clase. Sabía que tenía quince pesos en el bolsillo del pantalón y decidí tomar sólo otros quince pesos de mi escritorio (tres monedas de cinco pesos), suficiente para comprar algo. Ya que en mi plan original la operación se completaría en tan solo unos minutos tomé dos decisiones que después me parecieron peculiares: 1) conservé todo el tiempo los quince pesos que tomé del escritorio en la palma de mi mano derecha (jugueteaba con las tres monedas de cinco pesos) y 2) no llevé mi celular conmigo, me pareció que no tenía caso porque era muy temprano para que alguien me buscara por mensajero o me llamara; también porque no pensaba permanecer mucho tiempo fuera de casa. ${ }^{2}$

Caminé hacia el norte, hasta casi llegar al cruce entre Avenida del trabajo y el Eje 2, donde se encontraba un pequeño puesto de tamales (según mi breve aritmética, por treinta pesos podría hacerme con un tamal y un vaso de atole). Antes de cruzar la calle de Gorostiza pasé frente a un pequeño grupo de Testigos de Jehová, eran tres mujeres de la tercera edad, ataviadas con largas y grises faldas y suéteres de tonos pastel. Estaban paradas solemnemente junto a un pequeño stand con revistas acerca del fin del mundo y el próximo retorno del salvador. Después de cruzar la calle, me encontré con una construcción rodeada por tablones, una de esas obras que crecen como hongos en el barrio. Pocas son las viejas construcciones

\footnotetext{
${ }^{1}$ Presenté versiones previas de este trabajo tanto en el Seminario Permanente de Etnografía de la violencia a cargo de Natalia Mendoza Rockwell, como en el Seminario de etnografía urbana que fundé junto con otros jóvenes investigadores del Colegio de México y de la UNAM y que hoy integra también a compañeras y compañeros de otras instituciones como la UAM-I y el CINVESTAV del IPN. Agradezco a mis colegas y dictaminadores por sus generosas lecturas y comentarios.

${ }^{2}$ Una medida incorporada y claramente defensiva frente a la inseguridad local. Retomaré este tema sobre todo en el último apartado de este artículo.
} 
que desaparecen en la zona sin dar paso a nuevos y lujosos condominios con seguridad o en negocios que buscan gentrificar una zona que en realidad podría ser céntrica y deseable, de no ser por los problemas de criminalidad y violencia.

Los tablones que protegían la construcción y una alta jardinera de cemento paralela a ellos (que contenía un par de eucaliptos deteriorados y un montón de hierbajos) convertían la banqueta en un pequeño corredor por el que podían pasar como máximo un par de persona apretujadas. Desde antes de atravesar por ahí, había visto a un par de chicos parados en el angosto pasaje. Pensé que se trataba de dos albañiles de la obra. En ocasiones previas, había observado que algunos de los trabajadores más jóvenes permanecían ahí después de desayunar, fumando un poco de marihuana para hacer más cortas y llevaderas sus extenuantes jornadas en la construcción. Pero ese no era el caso, los dos chicos me interceptaron y me pusieron ágilmente contra la alta jardinera: había comenzado el asalto.

Lo primero que hice fue cumplir con el ritual: "no mamen, yo vivo aquí atrás", les dije y ellos me dieron una de esas respuestas descreídas que también se han integrado a la versión contemporánea del ritual: “jeso vale verga! ¡Saca el teléfono en corto!”. Me amagaron con sendas puntas, una se me clavaba en el costado derecho y la otra en el cuello del lado izquierdo. Sólo pude apreciar la de arriba, lucía extrañamente casera, como si a la usanza carcelaria se hubieran dado a la tarea de quitar la cabeza y afilar un cubierto que se robaron de algún cajón de la cocina de sus madres (una suerte de cuchara o tenedor con un colorido mango de plástico).

Eran dos veinteañeros, sus ligeros temblores y actitud eran como letreros luminosos de que andaban en piedra. El "piedroso" es el peor tipo de adicto enfiestado y armado con el que alguien puede encontrarse en un vecindario inseguro. El acelere que produce el crack y su corta duración, desembocan en general en una actitud voraz: los adictos siempre quieren más, dejan su dinero y posesiones en manos de los dílers con tal de obtenerlo. En el Tepito de finales de los noventa (en el que yo había sido socializado) había decenas de bromas acerca de cómo los piedrosos empeñarían cualquier cosa en medio de una juerga (su madre, el culo); todas imágenes obscenas y horrendas.

Uno de los chicos era moreno, tenía un rostro ancho, de labios gruesos y ojos ligeramente rasgados, era un poco más bajito que yo, algo así como un metro con sesenta centímetros, él sostenía la punta en mi cuello (ese juguetito rabioso). El otro era güero (blanco, de cabello castaño), más alto que su compañero y que yo, quizá rondaba el metro con setentaicinco. Aunque era sumamente delgado, parecía el músculo de la operación, era él quien me cerraba el paso y quien sostenía la punta en mi costilla (The boy with the thorn in his side).

Los dos llevaban atuendos de rapero, pantalones de mezclilla, tenis de basquetbol, gorras. El moreno lucía uno de esos blazers ligeramente elegantes, con dos hileras de tres botones al frente y una especie de boina. El güero vestía un hoodie negro sencillo y una gorra de beisbol. Cuando el moreno hablaba sus dientes bastante derechos se veían amarillentos y cubiertos de una extraña capa de sarro. Cuando el güero hablaba se veía que le faltaba un diente lateral. El descuido de la dentadura también es un rasgo asociado estereotípicamente 
con los adictos a la piedra y esa imagen también tenía sus chistes cotidianos ("síguele con esa madre, hasta que te quedes chimuelo", por ejemplo).

Miré de reojo a la esquina de la que venía, las testigos de Jehová contemplaban la escena rezando, si no supiera que a los protestantes no les gustan las representaciones, pensaría en la pintura de algún mártir; hubiera sido más útil llamar a una patrulla, pero cada quien ayuda con lo que tiene. "No traigo teléfono", dije como jactándome de mi afortunada decisión. “¿Cómo vergas no vas a traer teléfono?”, me dijo el güero con cara de exasperación, como sabiendo que habían elegido mal, que estaban algo así como robando a un cavernícola. “Qué van a hacer? ¿Robarme lo de mi desayuno?”, pregunté y a juzgar por su indignación y la insistencia con la que buscaban en todos los bolsillos de mi ropa, parecía que la respuesta era afirmativa. Pronto dieron con los quince pesos en el diminuto bolsillo de mezclilla a la derecha de mi pantalón. Los tomaron y huyeron con el envidiable botín.

Seguí mi camino entre la adrenalina y la indignación, "además me quedé sin atole", pensé hilando una idea boba, ese reflejo que a veces tenemos cuando hay desgracias. Los quince pesos en mi puño derecho seguían ahí, a nadie se le ocurrió revisarlo, siquiera formular un "arriba las manos", como en los viejos robos de la televisión, que quizá hubiera provocado que las monedas cayeran al piso. Mientras compraba mi tamal, me percaté de que los chicos sólo habían cruzado Avenida del trabajo y seguían ahí, expectantes, a un costado de una unidad habitacional. Supuse que esperaban otra víctima. En ningún lado conseguirían quince pesos de piedra, así que necesitaban más dinero para continuar con su aventura. Mi diagnóstico de señor tepiteño: eran el colmo del cinismo.

También pensé que unos pasos antes de llegar a la esquina de las testigos de Jehová, suele haber un retén permanente de la policía, casi siempre se trata de una camioneta con oficiales (aunque también puede ser una patrulla), que hace guardia permanente ahí, en una de las entradas principales al barrio. Normalmente sólo pasan el rato y de vez en cuando detienen a algún transeúnte o conductor de motoneta para realizarle una revisión de rutina. Hasta ese momento no habían aparecido, pero el ambiente ya estaba cargado de rezos. La camioneta apareció y avanzó lentamente por Avenida del trabajo hasta su puesto. Yo miré hacia los policías, hacia los chicos y algo en mi indignación lo activó todo: ¿qué tal si hubieran asaltado a las señoras, a mi abuela, a alguien más indefenso que yo o a alguien que portara un botín más sustancioso? "A traidor, traidor y medio", pensé, esos cabrones necesitaban un susto. Guardé mi tamal en mi chaleco y corrí hacia el retén de policías. Las señoras aplaudían y vitoreaban, como viendo un acto heroico de telenovela.

Mientras corría me percaté de que los chicos también habían decidido correr hacia la calle más cercana (Talabarteros). Cuando llegué a la ventana de la camioneta vi que había tres policías arriba, el del asiento trasero llevaba un rifle. "Me acaban de robar esos culeros que se echaron a correr”, les dije y el policía al volante gritó: “¡Súbete, moreno!”. Inmediatamente después de que me senté en el asiento trasero, el oficial hizo una de esas maniobras que sólo pueden hacer (sin meterse en líos) las personas que llevan placa: atravesó Avenida del trabajo con un extraño volantazo, se metió en sentido contrario por un pequeño carril y entró a la calle de Talabarteros. Desde la patrulla vimos cómo los chicos entraron a 
una pequeña unidad habitacional con una vistosa fachada amarilla. La camioneta se detuvo $\mathrm{y}$ los dos oficiales sentados al frente dijeron que iban a bajar a perseguirlos.

Esperamos unos minutos y yo pensé que mi misión estaba cumplida: porque no buscaba entregar a los malhechores a la justicia. Como ya mencioné, la fórmula en mi cabeza era "darles un susto" y a mi manera de ver, esa breve persecución policiaca era suficiente para arruinarles la mañana y la juerga. Con conocimiento de causa, le dije al oficial que no creía que fueran a atrapar a nadie. Se me ocurrieron un par de escenarios: a) que los chicos lograran su escape con agilidad, quizá incluso con la connivencia de los vecinos (siempre dispuestos a estorbar en una de estas operaciones policiales), b) que quizá en efecto vivieran en esa unidad y que pudieran esconderse en un departamento hasta que todo pasara, otra vez con colaboración (los escenarios en los que alguien entrega a un familiar o un vecino son raros y sólo ocurren cuando la misma familia o la comunidad también son víctimas de los agravios, aunque incluso en esos casos pocos comunes).

Me bajé de la camioneta y caminé de frente, mi plan era rodear la cuadra yendo hacia Avenida Circunvalación y después hacia la izquierda para volver a salir a Avenida del trabajo. Pensé: "si me encuentro de frente a esos cabrones, con o sin policías, ahora sí me van a picar". Apenas había doblado la esquina cuando me percaté de que el policía del rifle me llamaba:

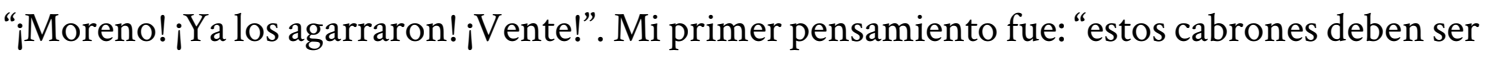
los peores ladrones del mundo". Cuando regresamos a la camioneta tenían detenidos a los chicos, el oficial que manejaba la camioneta me dijo: "se querían brincar a un techo, pero no pudieron y los agarramos": son definitivamente los peores ladrones del mundo.

El oficial que era copiloto me preguntó: “¿fueron ellos quienes te robaron?”. Apenas terminó de enunciar la pregunta y el chico moreno ya estaba replicando: "jah, nosotros te robamos, culero!”, el güero añadió: “'nosotros qué te vamos a robar?”. Ya sabía que eran torpes y cínicos, pero todo estaba llegando a niveles insospechados. Después de todo, habían corrido e intentado escapar con sus acrobacias poco efectivas. "Sí, ellos me robaron", repliqué. El chico moreno siguió con la perorata bravucona: “iyo no te robé, pendejo! ¡Yo no tengo ninguna necesidad! ¡Mira! ¡Mira!”, gritaba mientras nos mostraba una gruesa esclava que simulaba ser de oro en su muñeca izquierda y añadía: "ino sabes con quién te estás metiendo, pendejo! ¡No sabes quién es mi familia!”.

Los policías comenzaron con su propio ritual, el del amedrentamiento: "a mí se me hace que sí fueron ustedes y que seguro también le chingaron esa tableta a la muchacha de la madrugada", les dijo el copiloto. Les estaba "metiendo calambres", como se dice en el argot, quería hacerles saber lo arbitrario de su poder de uniformado, que les podían cargar mi robo y los que se les ocurrieran en ese momento. En lo que todo se aclaraba y en un país en el que la policía no investiga, el escenario es grave y suena siempre a encierro. Aunque creo que, como yo, el policía estaba apelando al miedo, que estaba blofeando y que era una forma de decirle al chico que se comportara.

Pero el chico moreno estaba enojado y cada vez más acelerado, no se iba a detener hasta estrellarse. Me gritó: "¡Yo no te pude robar, puto! ¡Porque además de todo estoy enfermo!” “¡Ah, estás enfermo!”, le grité. “¡Sí estoy enfermo!”, se abrió el blazer y se levantó la camiseta para mostrarnos una bolsa de diálisis pegada en su abdomen. No pude decidir si 
nuestras caras eran de sorpresa o de disgusto. "iNi porque traes esa madre, se te quita andar de culero!”, le grité, como si todas las señoras tepiteñas hubieran hablado por mi boca. Ya que en esa clase de caso los policías fungen como intermediarios en el tironeo, comenzaron a "meterme calambres” a mí también: “¿los vas a presentar o no los vas a presentar, moreno?”, me preguntó el chofer. Quería saber si iba a formalizar el proceso, pidiendo que arrestaran oficialmente a los chicos, para llevarlos ante un Ministerio Público, denunciarlos y poner en marcha el engorroso proceso legal. "Poli, me robaron quince pesos, ¡cómo cree! ¡El MP me va a mandar a chingar a mi madre!", le dije tratando de ser sensato.

En ese momento pensé que toda la interacción se estaba saliendo de control y que cada vez estaba en una posición más endeble: “a ver si no soy yo el que acaba detenido”, pensé, pero una vez más la piedra y sus humores inclinaron la balanza. El chico moreno que seguía siendo el más parlanchín, gritó: “ttú qué me ves, pinche chaparro!”, dirigiéndose al oficial que venía de copiloto. “¡Yo qué te veo de qué, hijo de tu puta madre!”, reviró el uniformado. “Pues lo que quieras, puto!”, respondió el chico y comenzaron a forcejear. Parecía un pleito de patio de secundaria, uno de esos enfrentamientos en los que un contrincante quiere derribar al otro y así mostrar su poderío. Ambos se estrellaron contra un auto estacionado, pero el chico se llevó la peor parte, porque quedó recargado de espaldas contra el automóvil. El oficial se zafó rápidamente y le conectó tres pequeños jabs de izquierda sin mucha técnica pero efectivos, porque le dieron en plena cara.

El chico moreno se tomó el rostro como si fuera una máscara que estaba a punto de caérsele, su gesto era de pura rabia. No arremetió directamente contra el oficial ni con golpes ni con insultos, sino que caminó tambaleante hacia la banqueta. Creo que todos nos tardamos en entender que estaba buscando algún objeto para responder a la agresión. Junto a un poste de luz encontró uno de esos tabiques que siempre están abandonados en las calles de los barrios "pa' lo que se ofrezca" y ahora lo que se ofrecía era un acto loco de venganza. Todos incluso su amigo, comenzamos a gritar suplicantes que no lo hiciera, que se calmara. " $¡ T e$ vas a meter en un pedo, morro!", grité. Pero él avanzó como en un viejo videojuego con el tabique por encima de la cabeza y ninguno de nosotros se atrevía a detenerlo: estaba rifando un viaje a la sala de urgencias y teníamos todos los boletos. El chico apuntó hacia el oficial y cuando estuvo a tiro de piedra (nunca una frase más adecuada), lanzó el tabique con fuerza. El copiloto boxeador volvió a hacer gala de sus reflejos, agachándose milagrosamente. El tabique se estampó en el cofre de la camioneta de policía.

Se desató el caos. Yo miraba para todos lados y sólo veía la expresión atónita de todos los otros involucrados. Un par de motos entraron en escena, cada una con un par de policías. Pensé que tal vez los oficiales habían emitido una señal al inicio de la persecución o cuando yo decidí alejarme de la camioneta. Tal vez estaban ahí porque nadie había contestado el radio durante toda la interacción. Tenía que tomar una decisión rápida y lo único que se me ocurrió fue desempolvar una vieja lección de Clifford Geertz: a veces lo más sensato que uno puede hacer es correr despavorido de la policía.

\section{Del código del barrio y las gestiones locales de la ilegalidad}


En los meses subsecuentes traté de componer una narración de corte etnográfico con las pequeñas notas que produje acerca del robo y para hacerlo utilicé una estrategia que Clifford Geertz (2013) adjudicó a Edward Evan Evans-Pritchard: convertí el incidente en un relato recurrente de mis reuniones de bar (y de unas versiones menos sórdidas que tuvieron como foco la cafetería del posgrado). Fue en esos encuentros que acuñé (en principio de manera bromista) la noción de código del barrio, para dar cuenta del pequeño intercambio ritual en el que expuse a mis atacantes las razones por las que no debían robarme, también me sirvió para explicar por qué en el punto más álgido del incidente, mi “identidad tepiteña” se había exacerbado hasta el punto de querer reprender a mis ladrones por un robo que cualquiera habría dejado pasar.

El tema de las gestiones culturales y locales del crimen es un clásico de la literatura antropológica y probablemente su texto inaugural (por lo menos en su faceta contemporánea) es Crimen y costumbre en la sociedad salvaje de Bronislaw Malinowski. Por eso decidí evocarlo desde el título de mi texto. Aunque ha pasado casi un siglo desde la elaboración de esa ponencia y muchos de los planteamientos del funcionalismo británico han perdido su brillo, me parece que la pugna de Malinowski por producir descripciones cada vez más adecuadas del crimen (basadas en material empírico) sigue vigente. Todavía hoy tenemos que sortear la tendencia a representar los espacios de ilegalidad como lugares plenos de caos, inmoralidad y desorden; o como espacios de sumo control y obediencia, en los que todas las formas de criminalidad parecen estar reguladas.

Los etnógrafos que nos hemos ocupado del tema del robo en diferentes espacios urbanos del continente americano, hemos continuado con esa discusión a nuestra manera, constatando empíricamente la existencia de códigos o reglas que dan forma a las prácticas ilegales en un sentido amplio, que dictan a quien se puede robar, dónde, en qué momento e incluso con qué grado de violencia y por tanto también dan forma a su reverso, a un conjunto de prácticas locales para evitar ser víctima de una agresión. Destaco por supuesto el trabajo clásico de Elijah Anderson (1999) acerca del código de la calle en el gueto negro de Filadelfia; pero igualmente me sirvo de los trabajos de jóvenes ladrones en los barrios de argentina como los de Sergio Tonkanoff (2016) o Eugenia Cozzi $(2015 ; 2018)$ y los que analizan el mismo fenómeno en las favelas brasileñas como los de Gabriel Feltran (2008), Carolina Grillo y Luana Martins (2020) o Sophia Prado (2020).

No tengo mucho espacio para revisar cada uno de los textos a detalle, pero trato de usarlos como un andamiaje que me permite dar forma a mi análisis del robo del que fui víctima y de las prácticas y representaciones culturales que de alguna manera le daban forma. Por ello, tal vez convenga que relate un poco de mi experiencia personal, que es además de mi breve narración de los hechos, la otra gran fuente de este trabajo. Cada vez que hablo de una generalidad cultural de Tepito lo hago basado en mi propia experiencia como varón socializado en el barrio. Mi familia llegó a Tepito después de periódicas mudanzas en los alrededores del centro de la Ciudad de México, en la coyuntura del terremoto de 1985: a la que entramos como damnificados y de la que salimos (como muchas otras familias), como novedosos propietarios de una vivienda. 
En el ambiente de las calles, de los nuevos y viejos predios (unidades habitacionales), de las vecindades y sobre todo del tianguis ${ }^{3}$, los niños fuimos acogidos sin mayor problema por los habitantes locales. ${ }^{4}$ De hecho, los vecinos, comerciantes o practicantes de algún oficio (casi siempre varones) que interactuaban con nosotros en las calles, nos instaban a defendernos de cualquier tipo de agravio utilizando un discurso que se resumía con la fórmula "diles que eres de aquî" o "diles que vives aquí". Lo que a mí manera de ver demostraba que, para todo efecto práctico, ya éramos tepiteños (y que debíamos incorporar algunos estándares acerca de lo que se esperaba de nosotros).

Teóricamente tomo distancia de la retórica funcionalista del código (Anderson, 1999), de las criminologías demasiado empapadas de Matza (Cozzi, 2015; 2018), de la idea del mundo del crimen que parece coquetear con Goffman o Becker (Feltran, 2008) o de los ecos foucaultianos de la noción de tecnologías del robo (Grillo y Martins, 2020). Yo interpreto al código del barrio como un principio de visión y de división del mundo, que generaba prácticas tanto en el ámbito de la ilegalidad, como en el de sus gestiones. Ese principio se regía por una oposición básica entre los locales (la gente que habitaba Tepito de diferentes formas) y los extraños e imponía por regla general que sólo se podía agraviar (robar o agredir) con relativa impunidad a estos últimos. ${ }^{5}$

Esta es una importante diferencia entre Tepito y otros espacios urbanos peligrosos (los guetos, barrios o favelas de los que se ocupan mis colegas). Los espacios urbanos designados como peligrosos tienden a desincentivar la presencia de extraños y convierten muchas de las cuestiones que competen a la gestión de la violencia y las ilegalidades en una discusión propia de los habitantes locales. Tepito es un lugar excepcional en ese sentido, por

\footnotetext{
${ }^{3}$ Los tianguis son espacios comerciales informales y callejeros, emblemáticos de la Ciudad de México. En su versión actual (porque existen con variantes desde el México prehispánico), se conforman de puestos móviles cuya estructura básica está construida con tubos, tablas y lonas de plástico. Justamente su peculiaridad es que no son fijos, salvo algunas excepciones como Tepito. Mientras que en otras partes de la Ciudad los tianguis se colocan una vez a la semana, en Tepito el tianguis permanece todos los días con excepción del martes y ocupa más de la mitad de la extensión original del barrio. En los tianguis se venden insumos básicos como alimentos, productos de cuidado personal o ropa, pero también incorporan objetos de moda, tecnología, mercancía pirata o incluso robada. Aunque son una práctica cultural legítima, de suma importancia para la población, mantienen una importante y permanente relación de tensión con las autoridades capitalinas. Tampoco me puedo detener demasiado en Tepito o en su caracterización, pero remito a los lectores interesados al clásico: Aréchiga, Ernesto (2003), Tepito: del antiguo barrio de indios al arrabal, México, Ediciones UnioS.

${ }^{4}$ Aquí mi tono se vuelve decididamente masculino, porque en el sentido de la gestión local de la violencia lo fue. Yo crecí además en una unidad familiar en la que sólo había mujeres adultas. No tengo notas o recuerdos acerca de cómo ocurrían esos procesos en lo que tocaba a las niñas, las adolescentes o incluso a la población con otras orientaciones o expresiones de género que por supuesto existían y existen en Tepito y en otros barrios (y que claramente experimentan socializaciones diferenciales con base en trayectorias que son más tempranas de lo que a veces se tiende a reconocer). Me parece que es un tema que debemos seguir explorando.

${ }^{5}$ Estoy operando la noción de habitus tal y como Bourdieu la define en El sentido práctico (2009). De todos los usos de la categoría para investigaciones etnográficas en contextos urbanos violentos que han hecho los discípulos de Bourdieu quizá con el que más me identifico es con el de Intimate apartheid de Bourgois y Shonberg (2007). Porque si bien trabajan con un escenario mucho más extremo (el de los vagabundos blancos y afroamericanos adictos a la heroína) se centra en una oposición entre dos tipos de pobladores y en las diferencias que se producen a nivel de las prácticas con base en esa distinción.
} 
ser un espacio predominantemente comercial con un gran peso en la cultura de la Ciudad de México. Usualmente, recibe importantes cantidades de visitantes de todo el país (e incluso del extranjero), que buscan adquirir mercancías legales e ilegales a precios relativamente accesibles; o simplemente, participar de alguna de las múltiples y novedosas prácticas culturales de sus habitantes (el culto a la Santa Muerte, los bailes de sonideros, el boxeo o la venta y consumo de estupefacientes pueden ser algunos ejemplos).

Es por esta razón que muchas personas que llevan dinero consigo (en ocasiones en buenas cantidades) u otros objetos de valor y que no están socializadas en el código del barrio (o no siempre pueden darle sustento) circulan por las calles como víctimas potenciales de un atraco. En lo que toca a este tema, también conviene señalar que me separo de cualquier abordaje identitario o culturalista (en el sentido más llano del término), porque no pienso que la identidad tepiteña sea ni un tipo de sustancia ni un conjunto rígido de características (materiales o simbólicas) de las que pueda ser fácil o inmediatamente deducible ni para una persona (la propia identidad) ni para un observador (la identidad de los otros); en todo caso, pienso que se trata del producto de una interpretación y negociación entre los agentes, que se actualiza de manera constante y que responde tanto a los contextos, como a múltiples mediaciones.

Hasta aquí todo puede parecer vana cháchara socioantropológica, pero creo que puedo aclarar mi posición al exponer algunas de las versiones típicas de robos gestionados con el código del barrio, descomponiéndolos en tres elementos constitutivos: el respeto, la posibilidad de venganza y la masculinidad. El respeto es central para los códigos que dan forma a la ilegalidad y que permiten gestionarla en los diferentes espacios locales. En el planteamiento clásico de Anderson (1999) aparecía en la forma de deferencia: al ser reconocidos como legítimos habitantes del gueto, los jóvenes socializados en el código tenían la posibilidad de eludir afrentas o agravios en el espacio público. Cozzi (2015) plantea un fenómeno similar cuando aborda la representación de las "víctimas inocentes" que son en su mayoría personas del propio barrio que están fuera de la "joda” y su planteamiento empata también con una idea expuesta en Mundo del trabajo, mundo del crimen de Diogo Lyra (2020), acerca de cómo los bandidos saben que antes que otra cosa son habitantes de una favela y comparten ese rasgo con gente que muchas veces creció con ellos exactamente en el mismo espacio. ${ }^{6}$

En Tepito, el código del barrio imponía la idea de que, ante una amenaza de robo, sin importar si se trataba de un robo a mano armada como el de mi narración, la posible víctima tenía que hacer gala de su temple y reiterar el hecho de que era un habitante del barrio y que,

\footnotetext{
${ }^{6}$ También merece mención la idea de los regímenes de circulación en el trabajo de Grillo y Martins (2020), aunque me parece que tiene una mayor complejidad. Al parecer en las favelas controladas por los grupos de narcotraficantes las ideas de respetar a los otros por su condición de vecinos o incluso de proletarios (gente que se gana la vida honradamente y no debería ser molestada), se imbrica con la necesidad de evitar problemas con unos cuerpos de policía que son claramente más eficientes y letales que los de mi relato. Por ello, las firmas imponen la regla de que se robe en un lugar que no sea la favela o en espacios de tránsito (como las paradas de autobús) y que en general no ingresen objetos difíciles de ocultar a su territorio (autos, cantidades importantes de mercancía robada).
} 
por esa razón, no entregaría ni su dinero ni sus pertenencias. Del lado del perpetrador se imponía un tipo particular de respeto o deferencia, ya que no sólo debía reconocer ese reclamo, sino que incluso debía propiciarlo, poniendo en marcha interacciones en las que la identidad de su víctima quedara clara. El ejemplo clásico era la práctica de abordar a los transeúntes pidiendo indicaciones para llegar a una calle particularmente conocida del vecindario (“¿Carnal, cómo salgo a Toltecas?”). Si el transeúnte no sabía que responder o aceptaba llanamente que no sabía, porque no era de Tepito, podía ser asaltado.

Esta clase de dinámica obligaba a los habitantes locales, sobre todo a los chicos que estábamos siendo socializados, a incorporar el sistema de clasificación local, a apropiarnos del espacio y a tomarnos el trabajo de conocerlo. También permitía que otros agentes con diferentes formas de habitar el barrio, por ejemplo, los clientes o visitantes recurrentes (que juegan un papel fundamental en la vida cotidiana) pudieran usar el código defensivamente. Aunque vale la pena señalar, que las interacciones no estaban libres de disputas o controversias. En ocasiones un asaltante podía requerir más pruebas para saber que estaba tratando con un local. No debe ser coincidencia que a veces preguntaran a la gente también de qué calle eran, en qué predio o vecindad vivían o directamente a quién conocían.

Esta clara alusión al capital social de la posible víctima, desemboca en el segundo elemento constitutivo, la posibilidad que tenía de vengarse o ser vengado, si de verdad era amigo, pariente, cliente o asociado de alguien que detentaba el suficiente reconocimiento en el barrio (de ser violento y respetado por ello, se sobreentiende). En las primeras páginas de un trabajo previo (Rivera, 2018), narro como uno de mis informantes claves, me sugirió que fuéramos al predio al que mis ladrones habían entrado al tratar de escapar a preguntar por ellos y a hacer directamente un reclamo por el agravio (sin importar que había ocurrido meses atrás y que el botín fue de tan sólo quince pesos). Esa clase de reclamos se podían hacer y eran comunes en la época de mi socialización en el barrio. Por supuesto, se tenían que hacer acompañado de la persona adecuada y debían llevarse a cabo con cuidado porque eran una declaración abierta de hostilidad. ${ }^{7}$

Hay por lo menos otro elemento constitutivo a analizar, y es justamente el del la masculinidad y su performance. Prácticamente no hay un trabajo etnográfico que hable del robo y de los códigos (Anderson, 1999; Cozzi, 2015; Caminhas y Beato Filho, 2020; Grillo y Martins, 2020; Lyra, 2020; Prado, 2020) que no los relacione con los rasgos estereotípicos del ser varón (sobre todo en los espacios de clase popular) como el poderío físico que raya en la crueldad (pelear, hacer daño a los otros o no tener empacho en hacerlo) o el temple, el vigor y la posibilidad de asumir riesgos, que se articulan en las trayectorias de los jóvenes

\footnotetext{
${ }^{7}$ Las obras de Cozzi $(2015 ; 2018)$ están plagadas de un ambiente en el que las vendettas entre diferentes grupos de jóvenes de "la joda" son permanentes, por más que estén de alguna manera pautadas; sobre todo en lo que toca a quienes son los legítimos involucrados (y por tanto legítimas víctimas de la violencia) y en los espacios en los que tienen que ocurrir las agresiones (siempre en las calles, nunca en sus espacios familiares o íntimos). En De juntas, clanes y broncas (2015), la autora reconoce escenarios sumamente similares al de mi robo: algún joven bajo el influjo de una sustancia "desconoce" a otro habitante del barrio y lo roba. Posteriormente tiene que responder respetuosamente, aceptando el reclamo de la víctima y devolviéndole sus pertenencias.
} 
dueños de la calle, muchas veces al cobrar la forma de cruzadas personales por respeto (reconocimiento, prestigio). ${ }^{8}$

En lo que respecta a los robos en Tepito debo señalar que, elegir a un transeúnte como una posible víctima implicaba, desde el punto de vista del agresor, que se trataba de un extraño (o por lo menos alguien desprovisto del reconocimiento que le permitiría eludir el agravio). Si la víctima era un legítimo habitante del barrio se esperaba de él no sólo resistir con temple el miedo producido por el asalto. La interacción imponía también mostrarse todo el tiempo como indómito y listo para repeler la agresión (o para intentarlo) haciendo uso de la violencia. Se trataba de un comportamiento claramente descabellado si se toma en cuenta que un robo de esta naturaleza puede involucrar a uno o más agresores, una o varias armas y un escenario pleno de incertidumbre. La posibilidad de terminar herido o muerto en una de estas interacciones es bastante real. A mi parecer, es una práctica inscrita claramente en la tendencia masculina a ponerse en peligro en aras de reconocimiento. Admitirlo parece cuando menos prudente, en un artículo en cuyas primeras páginas el narrador aparece amenazado por un par de puntas y resistiendo. ${ }^{9}$

En un sentido mucho más general (que puede incluso tener implicaciones en lo que toca a su génesis), me parece que el código funcionaba fundamentalmente para gestionar la violencia en un espacio relativamente abierto, no sólo al tránsito de los extraños, sino a su permanente asentamiento y (en ocasiones) a su conversión en habitantes locales. Una vez más pienso que el carácter fundamental de Tepito como un espacio comercial que atrae a un gran número de personas que buscan ganarse la vida realizando actividades dentro de sus calles; así como también, en su carácter relativamente céntrico y accesible en una ciudad plena de problemas para desplazarse o para acceder a servicios básicos. ${ }^{10}$

Dentro de los predios y de las vecindades, convergían en una proximidad que podía llegar a ser problemática grupos más bien heterogéneos de personas de clase popular, que tenían que gestionar su convivencia y frenar en la medida de lo posible, las agresiones y las vendettas que podían derivar de las mismas. Mucho más en un ambiente en el que a) prácticas informales e ilegales formaban parte del día a día y de los repertorios que los diversos grupos podían movilizar para garantizar su subsistencia y b) la violencia entre pares

\footnotetext{
${ }^{8}$ Con respecto al tema de la masculinidad, considero cuando menos prudente que comencemos a construir puentes hacia los estudios que han trabajado el crimen y las relaciones entre los géneros con seriedad. Me parece que el trabajo de Lobo de la Tierra (2016) produce ese engarce entre la antropología/sociología criminal y los estudios de género de una manera interesante.

9 Es porque la lógica de nuestras prácticas como víctimas parece todo menos lógica que difiero de la crítica de Loïc Wacquant a la forma en la que Elijah Anderson interpreta los robos: "El «código de la calle» es invocado aun en casos en los que resulta claramente superfluo: por ejemplo, no hace falta que alguien «adquiera el saber callejero del protocolo» del robo a mano armada para comprender que, cuando un asaltante le apunta en la cabeza, es mejor cooperar con él y acceder a sus pedidos” (2012: 67).

${ }^{10}$ En sentido estricto mi caso es exactamente el opuesto al del trabajo clásico de Elias y Scottson (2016). Ni el poder económico ni el tiempo de habitar en la comunidad (y noten que uso un verbo diferente de vivir) eran motivo suficiente para sostener una distinción permanente entre quienes ya eran tepiteños y quienes aspiraban a serlo.
} 
era una herramienta más para la resolución de conflictos, puesto que las intervenciones policiales cobraban muchas veces un carácter ominoso.

El asunto se tornaba problemático en el sentido de la proximidad. Entre los habitantes locales, que cohabitaban en los diferentes predios y vecindades normalmente se sabía quiénes se dedicaban a actividades ilícitas, a qué grupo familiar pertenecían, en dónde habitaban y en ocasiones algunas rutinas que podían convertir a alguien en endeble y a sus otros significativos en el blanco de una venganza. Todo parece bastante obvio y fácil de gestionar, pero creo que hay un par de elementos que en la realidad empírica tendían a complicar el asunto: el primero es el carácter de actividad que adquiría el robo para algunas personas, en la medida en que era un modo de subsistencia (una practicaba recurrente), en algún momento tenía que tomar como víctima a alguien local. El segundo es el tema del consumo de sustancias y su impacto en algunas de estas conductas (voy a desarrollar este tema en las próximas páginas).

\section{Una sustracción miserable}

En este apartado analizo la otra mitad de la interacción, la práctica ilegal que se supone el código del barrio trata de administrar: el robo. En México sabemos poco o nada acerca del robo (y casi todo lo que sabemos está plagado de mitos). Lo que constituye una suerte de ironía, ya que según las estadísticas oficiales, el robo es el delito más recurrente del país. ${ }^{11}$ En general es la práctica criminal que produce más miedo entre las personas de a pie, moviliza las opiniones más enardecidas de la cultura pública y la inversión más importante de recursos en lo que compete a la seguridad (individual o colectiva). Sorprendentemente, no existe tal cosa como la gran monografía antropológica del robo en México (a decir verdad, tampoco existen las pequeñas) y en lo que toca a la sociología nacional el panorama es igualmente desolador. ${ }^{12}$

El robo es una práctica fundamentalmente económica, en por lo menos dos sentidos. El primero, es el sentido clásico del concepto. Un robo implica una sustracción de dinero o de un bien, que más tarde puede intercambiarse por dinero. Es Sergio Tonkanoff (2016) quien nos recuerda que los robos podrían insertarse en repertorios de estrategias de reproducción que rebasan a los (casi siempre) jóvenes que los llevan a cabo, como las de los grupos familiares o incluso los barrios enteros. Sin embargo, incluso en los casos en los que alguien toma el robo como actividad y llega a considerarlo como un trabajo, funge como una entrada complementaria de dinero, cuya principal colaboración es el autofinanciamiento de

\footnotetext{
${ }^{11}$ Según los datos de la Encuesta Nacional de Victimización y Percepción sobre Seguridad Pública del año 2020 (INEGI, 2020), el robo a mano armada en sus dos modalidades clásicas (a transeúnte y en transporte público) se incrementó pese a la pandemia: se cometieron 9091 en 2019, frente a los 10775 de 2020.

${ }^{12} \mathrm{El}$ escenario en lo que respecta a la literatura sudamericana es ligeramente diferente. Los trabajos que han puesto el foco en el robo y otras prácticas criminales han sido más o menos constantes durante el último par de décadas. Sin embargo, tal y como señalan Luana Martins, Diogo Corrêa y Gabriel Feltran (2020), el contexto actual de muchos de nuestros países ha producido un vuelco casi total de la atención hacia el narcotráfico, opacando prácticas criminales que parecen menos espectaculares, por más que las estadísticas indiquen lo contrario.
} 
un miembro que puede dejar (aunque sea momentáneamente) de ser una carga para el resto del grupo.

El segundo sentido es el de lo que Bourdieu (2009) llamaba la economía de las prácticas. Es decir, la posibilidad de economizar, ahorrar o administrar de manera eficiente múltiples recursos, como la energía, el movimiento, la violencia. A decir de los autores especializados (Cozzi, 2015; Feltran, 2008; Katz, 1988; Kessler, 2004; Tonkanoff, 2016; Wright y Decker, 1997), robar armado a un transeúnte requiere relativamente poco entrenamiento $^{13}$ y si se hace bien es menos peligroso para los perpetradores que otras actividades ilegales, es más bien rápido, proporciona ganancias inmediatas que pueden adquirirse casi sin mediación e implica cumplir con un rol cultural que ya ha sido previamente asignado: el trabajo acumulado de ser un tipo duro (Anderson, 1999; Katz, 1988; Prado, 2020). ${ }^{14}$ Los asaltantes entrevistados en casi todas las investigaciones consideran que uno mejora con el tiempo. Podría decirse que practicar hace más práctica la práctica; o en cristiano: que robar se vuelve como quitarle un dulce a un niño (Wright y Decker, 1997: 42).

Hay por lo menos otro par de rasgos que se encuentran imbricados y que se enfatizan en los trabajos etnográficos dedicados al tema del robo. El primero es el carácter festivo y lúdico del ambiente de la calle, un espacio que privilegia diferentes formas de disfrute como el consumo de sustancias (destacan la bebida y diferentes tipos de estupefacientes) o las apuestas, todas actividades que requieren dinero, casi siempre en efectivo, para llevarse a cabo (Cozzi, 2015; Katz, 1988; Kessler, 2004; Prado, 2020; Tonkanoff, 2016; Wright y Decker, 1997). El segundo es el capital social, algunas de las redes a las que pertenecen los jóvenes que se dedican al robo tienden a fortalecerse, como las del reconocimiento entre los pares; mientras que otras tienden a debilitarse, como las del grupo familiar ${ }^{15}$.

Muchos familiares y amigos (que no llevan a cabo prácticas ilegales) ven a los agentes que roban habitualmente como personas que se aprovechan sistemáticamente de su confianza, que los explotan de manera constante y que difícilmente van a cambiar. El tipo de

\footnotetext{
${ }^{13}$ Entiendo el valor que pueden tener apuestas como la de Grillo y Martins (2020) para tratar de desmontar estereotipos acerca de las personas que roban o de los robos mismos e interpretarlos como tecnologías, como incorporaciones de vastos conocimientos que se deben poner en marcha en situaciones concretas y de la manera más adecuada. Sin embargo, me parece que lo que permite una interpretación más adecuada desde las nociones de habitus y de lógica práctica son tanto el papel de la incertidumbre (que las autoras constatan, por ejemplo, cuando hablan de la religiosidad de los asaltantes) que puede tergiversar cualquier plan por racional que sea y los ajustes que se hacen de estos planes que se deciden siempre al calor del momento y con base en un conocimiento que ya se lleva en el cuerpo.

${ }^{14}$ Creo que tenemos que seguir debatiendo este tema, porque hay contrastes interesantes en la literatura en trabajos como los de Cozzi (2018) o Diogo Lyra (2020) aparece una imagen opuesta. Sus informantes consideran que el narcotráfico puede ser una actividad menos riesgosa que el robo e incluso más parecida a un trabajo normal (en el que uno es explotado por alguien más). Por esa razón los robos se exaltan como prácticas heroicas, indómitas, propias de gente que no se somete a la autoridad de otros. Probablemente el contraste con México provenga de las penas sumamente endurecidas y de la violencia estatal directa contra el narcotráfico frente al tratamiento más bien laxo que en general se da a los robos.

${ }^{15}$ De hecho, el éxito callejero puede encubrir de forma importante otros fracasos en trayectorias como las escolares o laborales (por lo menos desde una mirada puesta en los valores más hegemónicos).
} 
gente que en el argot canero y barrial de la Ciudad de México suele denominarse como "agraviosa" (Reyes et. al., 2016). Por esta razón, se niegan a proporcionarles cualquier tipo de ayuda frente a un predicamento y muchas veces ni siquiera interpretan como uno las peticiones de ayuda o colaboración estos jóvenes.

Esto desemboca en la distinción que Wright y Becker (1997) proponen en su trabajo clásico entre "querer" y "necesitar" dinero. Alguien quiere dinero para sobrevivir, sostener su consumo y estatus y por supuesto pasarla bien. ${ }^{16}$ Pero en el caso de esta última pueden desatarse escenarios peligrosos de voracidad: cuando no puedes parar de consumir (alcohol o alguna otra droga) el dinero ya no se quiere, se necesita y muchas veces con urgencia. De hecho, los informantes de ese trabajo advierten que nadie debería enfiestarse sin contar con el dinero suficiente para sostener una farra, porque ese patrón casi siempre termina con un robo desesperado, en el que se hace caso omiso de cualquier regulación local (robar a quien sea sin importar de quien se trata); yo agregaría que también en un robo miserable (en el que se apuesta sin saber bien a bien cuál es el botín y no siempre se trata de uno bueno o deseable).

Me interesa destacar que la descripción de Wright y Becker (1997) comprende sustancias cuyo consumo tenemos más normalizado como el alcohol (que se relaciona con esos patrones de voracidad de lo que estamos dispuestos a aceptar). Sin embargo, algunos estupefacientes de consumo recurrente en la actualidad producen unos efectos todavía más letales cuando se trata de engancharse con el consumo. La literatura etnográfica de la ilegalidad ha documentado sobre todo el papel del crack. En algunos trabajos etnográficos relacionados con el robo y otros ámbitos ilegales (Bourgois, 2010; Contreras, 2013; Lyra, 2020), los adictos al crack aparecen como los participantes más erráticos y violentos de la vida en las calles y en el crimen, son considerados constantemente como problemáticos y en muchas ocasiones pueden llegar a ser relegados de operaciones delicadas o que requieren mucha mayor discreción o compromiso para llevarse a buen término.

Un dicho recurrente en las prisiones capitalinas es que "el dinero mal habido es malgastado". ${ }^{17}$ Una metáfora elocuente de ese atorón estructural en el presente. Un ladrón puede así obtener importantes cantidades de dinero que no producen algo más que puro y denso goce corporal. ${ }^{18}$ Parece imposible ignorar el cuerpo enfermo de mi principal atacante, que de manera interesante se encontraba velado. Probablemente ninguno de los participantes en aquella interacción (con excepción de su cómplice) se esperaba que un

\footnotetext{
${ }^{16}$ A esto me refería unas líneas más arriba. Las evaluaciones acerca de lo que se considera "necesario", producen choques entre las interpretaciones morales de los diferentes grupos. Algunos amigos y familiares pueden considerar que conservar una fachada o solapar el consumo y la fiesta no son de ninguna manera un predicamento que requiera de ayuda y pueden considerarlo como un desperdicio de recursos.

${ }^{17}$ Extraje el dicho y los comentarios que intercalo de la prisión de las notas de campo que produje entre 2017 y 2019, tiempo en el que fungí como profesor de asignatura en tres penales diferentes, dentro del programa que la Universidad Autónoma de la Ciudad de México tiene para ofrecer estudios universitarios a personas en reclusión.

${ }^{18}$ Jack Katz también reconoce ese patrón de "gasto súper rápido" o de "ganar y quemar el dinero" (1988: 214). Un ejemplo propio de la literatura latinoamericana puede encontrarse en el "régimen de las dos platas" de Gabriel Kessler (2004).
} 
temerario asaltante y consumidor de sustancias, llevara una bolsa de diálisis pegada al abdomen: un cuerpo que se desgaja en la aceleración y pese a ello no está dispuesto a detenerse. ${ }^{19}$

Todos estos elementos producen una rara mixtura. Como ya mencioné (y más allá de todos los clichés) los robos a mano armada (por lo menos los que se cometen contra transeúntes en cualquiera de sus modalidades), no requieren una gran planeación. De hecho, las víctimas se escogen más bien arbitrariamente, aunque los informantes de los diferentes trabajos (Caminhas y Beato Filho, 2020; Cozzi, 2015; Grillo y Martins, 2020; Prado, 2020; Tonkanoff, 2016; Wright y Decker, 1997) reconocen que suelen preferir algunas características (indicios relacionados con la etnia, el género o la edad) que les permitan deducir con base en la experiencia que alguien no opondrá tanta resistencia, elegir a la víctima en una zona por la que se desplace gente que se supone porta dinero ( $\mathrm{u}$ otros objetos de valor), tal vez incluso pensar en una zona en la que por la proliferación de las actividades ilícitas, mucha gente prefiera no dar parte a la policía con respecto al robo (Bourgois, 2010; Contreras, 2013). ${ }^{20}$

Esto me lleva justo a mi noción de sustracción miserable ${ }^{21}$ : un robo violento que dado su modus operandi es difícilmente perseguido o castigado y que propicia pequeñas transacciones que movilizan de manera constante algunas de las principales economías ilegales locales (como el narcomenudeo o la compra/venta de mercancía robada). Como mostré en mi narración, me encontraba en los predicamentos de: a) contravenir al código del barrio actuando en contra de mis ladrones que como yo eran habitantes del barrio, b) dar parte a la policía con su siempre ominosa presencia y c) denunciar un robo que parecía prácticamente una burla incluso para los mismos policías (un botín de quince pesos mexicanos).

Muchos robos miserables ocurren dentro de este marco en el que la gente prefiere renunciar a su dinero o a sus pertenencias, con múltiples justificaciones, como: no meterse en problemas con otros habitantes locales, suponer que la cantidad de dinero que les sustrajeron no fue grave o que los objetos que les robaron se pueden reponer (por ejemplo, un celular de uso cotidiano puede ser designado como viejo, deteriorado, algo que el dueño ya planeaba cambiar en cualquier momento). También está el supuesto nada imaginario de

\footnotetext{
${ }^{19}$ En las prisiones suelen llamar a esos aceleres de consumo y crimen, de manera bromista, "la calentura". Se cree que como buena "calentura" (las propias de la enfermedad o las sexuales) cederá en algún momento (sobre todo con la edad); pero mientras se encuentra activa es peligrosa, llama a una contención que nunca llega, a veces ni siquiera tras los muros y rejas de una prisión.

${ }^{20}$ Como ya he mencionado previamente, el trabajo de Grillo y Martins (2020) proporciona un contraste interesante porque en un escenario muy similar aparece la variable de los grupos del narcotráfico que pautan de una manera diferente tanto las prácticas ilegales, como la relación con la policía.

${ }^{21}$ Encuentro ciertamente una afinidad con la noción de microdelitos de Tonkanoff (2016) y me apoyo en su trabajo para mi análisis posterior. Sin embargo, me parece que en su enunciación abstracta se pierde el énfasis en el robo (aunque ciertamente se abre la posibilidad de dar cuenta de otros delitos), también se pierde un cierto matiz impregnado por la moral local (en este caso la que yo incorporé en mi barrio), que signa estas actividades como deplorables. Para ser justos, el mismo Sergio abordaba estas cuestiones en la parte más empírica de su trabajo, por ejemplo, cuando habla de ser rastrero o rastrillo.
} 
que denunciar un crimen en México es echar a andar un lento armatoste que se alimenta de copiosas cantidades de recursos (entre los cuales destacan nuevamente el dinero y el tiempo). La gente de a pie sabe que al denunciar se expone constantemente a prácticas de revictimización en las que puede terminar cuando menos humillada por las autoridades (yo mismo pensé que estaba permanentemente en riesgo cuando todo se complicó con la captura de mis nada hábiles asaltantes).

Sustracciones miserables como la que describí en mi relato articulan por lo menos tres conjuntos de prácticas que les imprimen un sello todavía más miserable. El primer conjunto de prácticas, son propias de las posibles víctimas que saben que no cuenta con las autoridades y que los mecanismos locales que les permitirían repeler un ataque no son efectivos en todas las situaciones. Por tanto, recurren a prácticas defensivas como portar menos dinero o pertenencias o hacerlo de maneras intrincadas que dificultan las labores de los asaltantes. En mi narración describí la búsqueda incesante y desesperada de mis atacantes en todos los bolsillos de mi ropa (en los que esperaban encontrar algo mínimamente digno). En la Ciudad de México, hay transeúntes que utilizan dobles de todo, usando unos patrones de sacrificio mimético que le provocarían una sonrisa a cualquier girardiano (llevar un celular peor que el personal para ser sacrificado, una cartera más vacía que la personal para entregar en el acto).

El segundo conjunto de prácticas pertenece a algunos ladrones (no creo que sea una representación que convenga extender a todos), que operan en ese marco en el que se ha exacerbado la necesidad de dinero para continuar con el consumo de sustancias y en el que es apremiante hacerse con algo, prácticamente con lo que sea y sin importar de quien venga (si es o no del mismo barrio) ni las consecuencias (si puede recurrir a sus redes para una venganza o dañar a la familia del victimario). Esto se relaciona con el tercer conjunto de prácticas, que involucran a esta clase de asaltantes/consumidores de sustancias y a los dílers locales que usualmente no hacen transacciones en especie o por lo menos no las hacen con adictos (un signo más del agotamiento de ciertos segmentos del capital social de estos agentes).

A diferencia de lo que las fantasías cotidianas puedan postular, muchos de los objetos que se obtienen en las sustracciones miserables no integran grandes circuitos de reventa en mercados y plazas, (si alguien pusiera en un puesto de tianguis las mercancías que normalmente se roban a los transeúntes, sería en un puesto de chácharas ${ }^{22}$ ). Más bien vuelven a integrarse a pequeños circuitos locales de la ilegalidad (Feltran, 2008; Tonkanoff, 2016) en los que los recursos se aprovechan de manera extensiva y que permiten a los habitantes locales hacerse con objetos para mejorar o sostener su fachada (en el caso de los más jóvenes) o que simplemente ayudan a solucionar problemas del día a día. Siempre hay alguien en un predicamento (a veces también una víctima reciente de la inseguridad) que requiere, por ejemplo, un teléfono celular funcional. Así es como cerca de los puntos de venta

\footnotetext{
${ }^{22}$ En español mexicano una "cháchara" es un objeto usado, una baratija. Es común encontrar puestos que venden esa clase de objeto en los tianguis, aunque sus precios son casi de regalo (o así lo han sido tradicionalmente).
} 
de droga o por efecto de las redes propias de sus participantes, se malbaratan algunos objetos que permiten continuar con la fiesta, cuando las cosas salen bien y no acaban en extravagantes narraciones para revistas de ciencias sociales.

\section{Conclusiones}

A medio camino entre el diario de campo y el diario íntimo, escribí en las líneas con las que prometí este texto. Así fue como escribí y así era como me sentía tanto en el momento de producir mi narración, como en los análisis posteriores. Antes de que ese par de jóvenes del barrio en el que crecí me "desconocieran", ya lo habían hecho algunos de mis empleadores. Regresé a mi lugar de origen, aunque ya no fuera exactamente el mismo, con mi novedoso equipamiento: un bagaje de herramientas etnográficas que me permitía construir interpretaciones que no tenía previamente acerca de Tepito o de mi propia socialización. Todos estos hechos me obligaron también a hablar, aunque fuera un poco de ese lugar incómodo que ocupo dentro de la producción del conocimiento: en circunstancias ligeramente diferentes, yo sería un informante clave y no un etnógrafo.

El robo del que fui víctima fue uno más de los incidentes violentos que se acumulan por montones en las monografías antropológicas clásicas, en los que al fin se rompe el hielo con los habitantes locales. Después del asalto comencé a hacerme preguntas acerca de un conjunto de prácticas que también estaban de alguna manera fuera de lugar. Nuestras viejas narrativas acerca del respeto eran poco menos que habladurías de los señores del barrio para las nuevas generaciones (aunque quizá siempre lo fueron para los miembros más indómitos de mi generación y las previas). Nunca he sido partidario (por lo menos no etnográficamente) de las narrativas melancólicas, tal vez alguien esté en este momento documentando prácticas más eficientes (y quizá no por ello menos violentas) para administrar la ilegalidad en Tepito o en otros barrios. Pero no puedo evitar pensar en ese Malinowski extrañamente preocupado por el cambio, que hablaba de cómo siempre escribimos acerca de cosas que tienden a desaparecer.

La etnografía es en muchos sentidos un diálogo, como se puede constatar por nuestras principales técnicas (casi todas conversacionales). Aunque mis interlocutores locales y yo nunca estuvimos en situación de entrevista, sí mantuvimos una serie de intercambios (casi todos comunicativos) que nos permitieron de algún modo objetivarnos mutuamente (por más que fuera yo el que detentara la forma hegemónica de escritura). Normalmente los (des)encuentros con los posibles informantes cobran formas más elegantes en su violencia, pero bien llevados a cabo producen siempre el necesario efecto de extrañeza para mover el lápiz o sentarse por largas sesiones frente a la computadora, para hablar un poco de los otros y un mucho de uno mismo.

La escritura etnográfica es de suma importancia para describir microscópicamente prácticas de las que sabemos poco o nada (también de las que se producen mitologías de manera incesante). Sorprendentemente (como decía en alguno de los pasajes previos de este escrito), en un país tan pleno de violencia, crimen e ilegalidad como México, seguimos sin saber demasiado de esas realidades, de prácticas tan cotidianas como robar o ser robado, sobrevivir al día a día en una de las ciudades más violentas del orbe. Yo pensé este trabajo 
así, como una pequeña colaboración para entender más de la vida y el crimen en el barrio. Ahí donde los límites de la acción policial se negocian y dibujan a cada momento.

Imagino a algunos de mis colegas etnógrafos nativos como yo (que hoy se cuentan por montones) o en algunos otros que son observadores más clásicos, todos comprometidos por largo tiempo con terrenos que son tan violentos como Tepito o quizá más (siempre les gusta bromear con el uso imaginario de un violentómetro), diciendo que lo que narro en estas líneas no ocurre sólo en este espacio ni de esta manera ni me ha ocurrido sólo a mí. Pienso que, si este trabajo propicia esa clase de interpelación, podríamos producir una provechosa conversación acerca de cómo los sistemas clasificatorios locales se usan para gestionar algunas prácticas criminales, cómo ayudan o no a gestionar violencias que pueden incluso llegar a ser brutales. Porque todas ellas siguen dejando marcas permanentes en los cuerpos de personas reales en las que se inscriben y esa es sobre todo la realidad que nos gustaría imaginar de forma diferente.

\section{Referencias}

ANDERSON, Elijah. 1999. Code of the Street. Decency, Violence and the Moral Life of the Inner City, New York, W. W. Norton \& Company.

BOURDIEU, Pierre. 2009. El sentido práctico. Ciudad de México: Siglo XXI.

BOURGOIS, Philippe; SHONBERG, Jeffrey. 2007. “Intimate Apartheid. Ethnic Dimensions of Habitus among Homeless Heroin Injectors”. Ethnography, Vol 8, n. 1: 7-31. DOI $10.1177 / 1466138107076109$

BOURGOIS, Philippe. 2010. En busca de respeto: vendiendo crack en Harlem. Buenos Aires: Siglo XXI.

CAMINHAS, Diogo; BEATO FILHO, Cláudio. 2020. “Todo ladrão vai trabalhar com a sua mente’: O uso da força e de armas nos assaltos em Belo Horizonte, Minas Gerais”. Dilemas - Revista de Estudos de Conflito Controle Social, vol. 13, n. 3: 645-667. DOI 10.17648/dilemas.v13n3.31676

COZZI, Eugenia. 2015. "De juntas, clanes y broncas: regulaciones de la violencia altamente lesiva entre jóvenes de sectores populares en dos barrios de la ciudad de Santa Fe". Delito y Sociedad, vol.1, n. 39: 72-102. DOI 10.14409/dys.v1i39.5568

COZZI, Eugenia. 2018. “Se les doblo el caño, perdieron el honor'. Prácticas, representaciones y valoraciones en relación con la participación de jóvenes en robos y en el mercado de drogas ilegalizadas en un barrio de la ciudad de Rosario". Cuestiones Criminales, año 1, n. 1: 1-21.

CONTRERAS, Randol. 2013. The Stickup Kids: Race, Drugs, Violence and the American Dream. Berkeley: University of California Press.

Elias, Norbert; SCOTSON John L. 2016. Establecidos y marginados. Una investigación sociológica sobre problemas comunitarios. México: Fondo de Cultura Económico.

FELTRAN, Gabriel. 2008. "O legítimo em disputa: as fronteiras do "mundo do crime" nas periferias de São Paulo”. Dilemas - Revista de Estudos de Conflito e Controle Social, vol. 1, n. 1: 93-126. DOI: 
GRILLO, Carolina Christoph; MARTINS, Luana. 2020. "Indo até o problema: roubo e circulação na cidade do Rio de Janeiro". Dilemas - Revista de Estudos de Conflito Controle Social, vol. 13, n. 3: 565-590. DOI: 10.17648/dilemas.v13n3.32078

GEERTZ, Clifford. 2013. El antropólogo como autor. Barcelona: Paidós.

KATZ, Jack. 1988. Seductions of Crime: Moral and Sensual Attractions in Doing Evil. New York: Basic Books.

KESSLER, Gabriel. 2004. Sociología del delito amateur. Buenos Aires: Paidós.

LOBO DE LA TIERRA, Alberto. 2016. "Essentializing Manhood in "the Street": perilous masculinity and popular criminological ethnographies”. Feminist Criminology, Vol. 11, n.4. DOI 10.1177/1557085116662313

LYRA, Diogo. 2020. “Operários da Firma: Mundo do Trabalho no Mundo do Crime”. Revista Antropolítica, n. 50: 84-106. DOI: 10.22409/antropolitica2020.i50.a43306

MARTINS, Luana; CORREAA, Diogo; FELTRAN, Gabriel. 2020. “Apresentação ao dossiê Roubo, Violência e Cidade”. Dilemas - Revista de Estudos de Conflito Controle Social, vol. 13, n. 3: 557-564. DOI 10.17648/dilemas.v13n3.36176

PRADO, Sophia. 2020. "Vivendo o roubo: Um momento de adrenalina, deleite e performance”. Dilemas - Revista de Estudos de Conflito Controle Social, vol. 13, n. 3: 669690. DOI 10.17648/dilemas.v13n3.31683

REYES, Rigoberto; CÉSAR, Huerta, Julio; BOY, Dany; ALEXIS, Ochoa Pastrana. (Eds.). 2016. Glosario canero. Definiciones desde los Niños de oro. México, Ediciones Círculo errante de estudio y discusión anarquista.

RIVERA, Jovani J. 2018. En una esquina de Tepito. Diario de campo, México, Colegio de México.

TONKANOFF, Sergio. 2016. "Microdelitos, juventudes y violencias: La balada de los Pibes Chorros”. Delito Y Sociedad, vol.1, n. 18/19: 109-124.

WACQUANT, Loïc. 2012. Merodeando las calles: trampas de la etnografía urbana. Barcelona: Paidós.

WRIGHT, Richard; DECKER, Scott H. 1997. Armed Robbers in Action: Stickups and Street Culture. Boston: Northeastern University Press.

resumo Depois de ser assaltado pela última vez em Tepito (bairro onde cresci na Cidade do México), fiz um relato do incidente a meio caminho entre o diário de campo e o diário privado com o qual me propus a analisar dois fenômenos: o primeiro são os princípios que incorporei durante a minha socialização no bairro e que antigamente permitia administrar a ilegalidade, embora sempre com limites, rupturas ou adaptações (como é conhecido pelos estereótipos e imagens que circulam na cultura pública nacional, os roubos são cotidianos atua em Tepito). O segundo é uma forma particular de roubo que chamei de roubo miserável, um roubo violento que, dado o seu modus operandi, dificilmente é processado ou punido e que incentiva pequenas transações que mobilizam constantemente algumas das principais economias locais ilegais (tráfico de drogas, compra / venda de mercadoria roubada).

palavras-chave roubo a mão armada, crack, Tepito, habitus 
Jovani Rivera Gutiérrez

Candidato a Doctor en Ciencias Políticas y Sociales con especialidad en Sociología, Universidad Nacional Autónoma de México.

Autoría: El autor fue responsable por la recogida, sistematización y análisis de los datos, así como de la escritura del artículo.

Financiación: La escritura de este artículo no contó con beca de apoyo a la investigación.

Recibido en: 30/06/2021

Fecha de aceptación 24/11/2021 